\title{
MANAJEMEN TEAM TEACHING MATA KULIAH KEPRAMUKAAN DI PROGRAM STUDI PENDIDIKAN DASAR ISLAM
}

\author{
Rustam Supriyanto \\ Pusdiklatcab Satria Guna Kwarcab Probolinggo, Indonesia \\ Email :rustamsupriyanto@gmail.com \\ Farhan \\ Universitas Nurul Jadid Probolinggo, Indonesia \\ Email : farhan.alim11@gmail.com
}

\begin{abstract}
Artikel ini menjelaskan pentingnya kolaborasi dan sinergi dalam manajemen team teaching antara dosen dan pelatih Pramuka mewujudkan ketercapaian ketuntasan pembelajaran kepramukaan pada program studi pendidikan dasar Islam. Penelitian ini merupakan kajian pustaka dengan pendekatan konseptual. Pemilihan dan pemilahan data yang relevan dilakukan untuk kemudian di analisis secara deskriptif kualitatif. Rumusan penelitian adalah bagaimana manajemen team teaching mata kuliah kepramukaan program studi pendidikan dasar Islam? Hasil penelitian menyatakan: pertama; team teaching dimulai dan atas dasar adanya MoU program studi atau fakultas dengan pelatih pembina pramuka. Kedua; team teaching kepramukaan berkolaborasi secara berkelanjutan dalam pelaksanaan atau pendidikan kursus mahir dasar dan lanjutan. Ketiga; team teaching penguatan peran pusdiklat dan puslitbang dalam penelitianpublikasi dan pengabdian masyarakat bidang kepramukaan. Keempat; team teaching dalam penilaian pendistribusian mahasiswa pembina Pramuka bagi golongan siaga dan penggalang sebagai uji kompetensi calon guru profesional secara berkelanjutan.
\end{abstract}

Kata Kunci : Team Teaching, Kepramukaan, Kurikulum, KMD.

\section{Pendahuluan}

Persoalan pembinaan pramuka di perguruan tinggi masih membutuhkan perhatian yang cukup serius dari para pemangku kebijakan yang sekaligus merupakan anggota dewasa. Anggota dewasa adalah anggota gerakan pramuka yang berusia 26 tahun ke atas atau 
berusia diatas 21 tahun dengan catatan sudah melepaskan status sebagai anggota muda (khususnya Penegak dan Pandega), atau sudah menikah atau sudah memiliki Surat Hak Bina (SHB). ${ }^{1}$ Rentang usia mahasiswa pada umumnya adalah usia pramuka penegak (16-20) dan atau pramuka pandega (21-25). Karena itu, mahasiswa yang pernah aktif di gerakan pramuka sejak SLTA, dan sebagian sudah memiliki sertifikat Kursus Mahir Dasar (KMD) dengan SHB dari kwartir setempat berhak untuk menjadi Pembina pramuka baik pada tingkat golongan siaga maupun golongan penggalang.

Gerakan pramuka memiliki regulasi yang tertata dengan manajemen yang sistematis dan terencana dengan baik secara berkesinambungan. Penggolongan keanggotaan peserta didik digolongkan berdasarkan usia; siaga usia 7 sampai 10 tahun, penggalang usia 11 sampai 15 tahun, penegak usia 16 sampai 20 tahun, dan Pandega usia 21 sampai 25 tahun. ${ }^{2}$ Pramuka penegak yang sudah lulus dari SLTA umumnya terus melanjutkan ke jenjang perguruan tinggi dengan status mahasiswa. Mahasiswa bisa melanjutkan jenjang pendidikan di dalam UKM Pramuka. Walaupun secara usia belum mencapai 21 tahun, mayoritas mahasiswa kemudian aktif di racana pandega.

Bagi perguruan tinggi yang telah memiliki program studi calon sarjana guru, dapat mensinergiskan para mahasiswa dalam pengabdian mahasiswa melalui program magang atau praktik pengalaman lapangan (PPL) sebagai para pembina dan atau pembantu pembina pramuka di golongan siaga dan penggalang.

\footnotetext{
${ }^{1}$ Joko Mursitho, dkk. Keputusan Kwartir Nasional Gerakan Pramuka Nomor 201 tahun 2011 tentang Sistem Pendidikan dan Pelatihan dalam Gerakan Pramuka. Jakarta: Kwartir Nasional Gerakan Pramuka, 2011. http://bandung19.or.id/wp-content/uploads/2013/04/640321_SistemPendidikan-dan-Pelatihan-dalam-Gerakan-Pramuka.pdf (diakses pada 12 Februari 2020).

2 Undang-undang tentang Gerakan Pramuka, Pasal 17 ayat 1 dan 2 , http://hukum.unsrat.ac.id/uu/uu2010_12.pdf (diakses pada 12 Februari 2020).
} 
Minimnya proses kolaborasi dan kerjasama yang terjalin antara pemangku kebijakan di perguruan tinggi menjadi 'pekerjaan rumah' bagi semua tingkatan kwartir. Termasuk, minimnya program studi calon sarjana yang memiliki kualifikasi mata kuliah kepramukaan sebagai mata kuliah penunjang program studi. Ismail Suardi Wekke mengungkapkan pengembangan pembinaan pramuka di perguruan tinggi perlu mendapatkan perhatian serius untuk diintegrasikan dengan programprogram di semua tingkatan kwartir. Karena salah satu kekuatan gerakan pramuka adalah kohesi sosial yang sudah terbangun dengan baik. ${ }^{3}$

Bagi Wekke peguruan tinggi dapat mensinergiskan tri dharma perguruan tinggi dengan program kwartir melalui pusat pendidikan dan pelatihan (pusdiklat) dalam bentuk kegiatan kursus Mahir Dasar (KMD). Karena surat ijazah yang didapatkan dari KMD bisa menjadi Surat Keterangan Pelengkap Ijazah (SKPI) bagi setiap mahasiswa. Sehingga ketika sudah menjadi seorang sarjana, lulusan sudah siap bertugas secara professional sebagai tenaga pendidik bersertifikat plus. Misalnya, bagi prodi Pendidikan Guru Madrasah Ibtidaiyah (PGMI), menurut Wekke, bisa ditentukan bobot sistem kredit semester antara 2 sampai 3 sks untuk mata kuliah kepramukaan.

Para sarjana PGMI yang telah mendapatkan mata kuliah kepramukaan dengan didukung pengalaman lapangan yang intensif dalam pembinaan pramuka siaga dan penggalang, akan terasah keterampilannya sebelum benar-benar menjadi seorang sarjana. Karena, pasca KMD pun masih terdapat proses pengembangan diri dalam pelaporan narakarya selama kurang lebih satu semester atau 6 bulan.

\footnotetext{
${ }^{3}$ Ismail Suardi Wekke, Tata Kelola Pembinaan Pramuka Di Perguruan Tinggi. Makalah prasyarat mengikuti kursus pelatih dasar (KPD) Kwartir Daerah Bandar Lampung 23 Februari s.d 1 Maret 2018, 2018. http://www.academia.edu/download/55941907/Pembinaan_Pramuka_di_Perti.pdf (diakses 18 Maret 2020).
} 
Hal tersebut sangat relevan dengan peraturan menteri pendidikan dan kebudayaan Republik Indonesia nomor 63 tahun 2014 tentang pendidikan kepramukaan sebagai ekrakurikuler wajib pada pendidikan dasar dan pendidikan menengah. Artinya, akan terjalin harmonisasi antara perguruan tinggi dengan gugusdepan-gugusdepan berpangkalan di sekolah dasar dan menengah dalam penguatan revitalisasi gerakan Pramuka. sebagaimana dipahami, bahwa empat tahun sebelum adanya permendikbud RI, revitalisasi gerakan pramuka didengungkan oleh presiden SBY pada tahun 2010 melalui disahkannya undang-undang Gerakan Pramuka.

Menurut Andi Mallarangeng, -menteri pemuda dan olahraga ke-10 masa kepemimpinan Susilo Bambang Yudhoyono yang menjabat 22 Oktober 2009 sampai 7 Desember 2012-, menyebutkan bahwa disahkannya Undang-undang gerakan pramuka akan memberikan ruang lebih luas bagi partisipasi anggota dewasa untuk terlibat dalam pendidikan kepramukaan. ${ }^{4}$ Sehingga keberperanan anggota dewasa semakin mendapatkan tempat yang besar dalam menanamkan nilai-nilai pendidikan karakter bagi peserta didik.

Kegiatan kepramukaan memiliki prinsip dasar kepramukaan dan metodik kepramukaan yang khas, didukung dengan sistem 'Among' ala Ki Hajar Dewantara. Sistem among yang dimaksud yaitu; Ing Ngarsa Sung Tulada (di depan membangun keteladanan), Ing Madya Mangun Karsa (di Tengah memberi semangat), dan Tut Wuri Handayani (di belakang memberi dukungan). ${ }^{5}$ Sehingga gerakan pramuka mampu menjadi wadah yang kuat dalam proses kaderisasi dan menciptakan kader bangsa yang

4 Kemenkumham RI, Andi Mallarangeng: UU Gerakan Pramuka Perkuat Revitalisasi http:/ / ditjenpp.kemenkumham.go.id/berita-hukum-dan-perundang-undangan/841andi-mallarangeng-uu-gerakan-pramuka-perkuat-revitalisasi.html, Berita (diakses 18 Maret 2020)

5 Wangid, M. Sistem Among Pada Masa Kini: Kajian Konsep dan Praktik Pendidikan. Jurnal Kependidikan: Penelitian Inovasi Pembelajaran, 2019,. doi:https:// doi.org/10.21831/jk.v39i2.200. (diakses 18 Maret 2020) 
berkarakter. Baik dari jenjang golongan siaga, penggalang, penegak hingga golongan pandega.

Gerakan pramuka dapat menjadi alternatif dalam pendidikan karakter kedisiplinan. ${ }^{6}$ Peserta didik akan di cetak menjadi manusia berwatak, berkepribadian Indonesia dan berakhlak mulia. Pramuka siaga, misalnya, penguatan karakter melalui beragam kegiatan permainan ala pramuka, diperkuat dengan kode kehormatan. Bagi pramuka siaga terdiri dari; Dwi Satya (janji dan komitmen diri), berbunyi; (1) Menjalankan kewajiban terhadap Tuhan yang Maha Esa, Negara Kesatuan Republik Indonesia dan menurut aturan keluarga, (2) setiap hari berbuat kebaikan, dan Dwi Darma (ketentuan moral) yang berbunyi siaga berbakti pada ayah dan ibundanya, siaga berani dan tidak putus asa. ${ }^{7}$ Intan Kusumawati menguraikan bagaimana gambaran tentang pembinaan sebagai proses pembentukan karakter dalam pramuka siaga:

“Dalam pembinaan Siaga, suasana keluarga bahagia ini dialihkan ke lapangan tempat latihan Siaga di alam terbuka. Di tempat latihan juga ada "ayah" yang dipanggil Yanda, "ibu" yang dipanggil Bunda, "bibi" yang dipanggil Bucik dan paman yang dipanggil Pakcik. Pada golongan Siaga wadah pembinaannya disebut Perindukan Siaga sesuai dengan kiasan dasar bahwa Siaga masih 'menginduk" pada keluarganya. Kegiatan di Perindukan Siaga terdiri atas: Latihan mingguan dan kegiatan bersama. Bahan/materi latihan mingguan dan kegiatan bersama mengacu pada materi SKU. Acara latihan mingguan hendaknya didahului dengan upacara pembukaan latihan, dilanjutkan dengan kegiatan yang ramai atau riang, kegiatan tenang, diselingi nyanyian/ tarian/dongeng/cerita dan diakhiri dengan upacara penutupan latihan." ${ }^{8}$

\footnotetext{
${ }^{6}$ Nur Qoyimatul Uyun Al Azizi, 2020, Kegiatan ekstrakurikuler kepramukaan terhadap pendidikan karakter kedisiplinan. Jurnal Pendidikan Luar Sekolah, Vol. 12, No. 2, 2018, h. 40-50.

7 Pasal 23 tentang Kode Kehormatan Pramuka dalam AD ART Gerakan Pramuka hasil Musyawarah Nasional nomor: 08/munas/tahun 2018.

8 Kusumawati, I. (2012). PEMBENTUKAN KARAKTER SISWA MELALUI PENDIDIKAN KEPRAMUKAAN. Academy of Education Journal, 3(1). Retrieved from https://jurnal.ucy.ac.id/index.php/fkip/article/view/85. (Diakses 18 Februari 2020).
} 
Penelitian Saadah Erliani juga menyatakan peran gerakan pramuka juga mampu berperan dalam membentuk karakter peserta didik memiliki kepedulian sosial dan kemandirian sejak dini. Siswa kelas lima SDIT Ukhuwah dan MIS An Nuriyyah 2 Banjarmasin, menurut Erliani, menunjukkan indikator kepedulian sosial dan kemandirian yang signifikan, melalui kegiatan latihan rutin mingguan, upacara, permainan, api unggun, penjelajahan, gelang senja, lomba tingkat dan jambore dan seterusnya. ${ }^{9}$

Kepramukaan bagi para mahasiswa prodi PPKn FKIP Universitas Muhammadiyah Surakarta, bahkan dilakukan pada empat kali pemograman semester, yaitu pada semester I, II, IV dan VIII. Pada dua semester pertama mahasiswa banyak mempelajari teori, sedangkan pada semester keempat mahasiswa melaksanakan KMD, sedangkan semester delapan adalah KKL. Secara umum respon para mahasiswa, menurut penelitian Sri Arfiah dan Agus Prasetya, keberadaan mata kuliah kepramukaan tersebut sangatlah bermanfaat. Para mahasiswa memiliki karakter kemandirian dan tanggungjawab. Mahasiswa memiliki tambahan kepercayaan diri, menghargai keberagaman, berpikir logis, kritis, kreatif dan inovatif dan sebagainya. Mata kuliah kepramukaan yang telah dipelajari dan dipraktekkan mampu meningkatkan kualitas lulusan. Selain menjadi guru mata pelajaran, para alumninya memiliki kompetensi tambahan sebagai Pembina ekstrakurikuler pramuka. ${ }^{10}$

Sama halnya dengan karakter mahasiswa di Universitas Riau yang aktif di UKM Pramuka memiliki karakter yang baik. Penelitian Jumili

9 Erliani, Saadah. "Peran Gerakan Pramuka Untuk Membentuk Karakter Kepedulian Sosial Dan Kemandirian." Al-Adzka: Jurnal Ilmiah Pendidikan Guru Madrasah Ibtidaiyah [Online], 7.1 (2017), 2017, (Diakses 18 Februari 2020)

${ }^{10}$ Sri Arfiah dan Agung Prasetya, Pembelajaran kepramukaan dalam penguatan Karakter Kemandirian dan tanggungjawab dalam upaya mempersiapkan mahasiswa PPKN sebagai Pembina Ekstrakurikuler di Sekolah, URECOL, the $6^{\text {th }}$ University Research Colloquium, 2017.

$\underline{\text { http://journal.ummgl.ac.id/index.php/urecol/article/view/1368/799 }}$ (Diakses 18 Februari 2020) 
Arianto, menyatakan bahwa ada pengaruh yang sangat baik adanya UKM pramuka terhadap pembentukan karakter jujur. Dari populasi penelitian anggota pramuka yang aktif tahun 2016 sebanyak 80 orang, dari pernyataan 'berkata jujur dan sopan dalam kelompok', sebanyak 60 responden atau 75 persen menyatakan sering berkata jujur dan sopan dalam kelompok, dan hanya 20 responden atau 25 persen yang menjawab kadang-kadang. ${ }^{11}$ Penelitian diatas merupakan hasil penelitian yang menunjukkan betapa penting dan vital organisasi gerakan pramuka dalam pembentukan karakter dan wadah kaderisasi, terlebih di era kekinian, dimana setiap individu pemuda (mahasiswa) dihadapkan kepada tantangan beragam 'warna', mulai dari ancaman kehilangan identitas, terjadinya stress, bahkan tindakan kriminalitas disebabkan perilaku pemuda yang 'tidak bertanggungjawab' terhadap diri, keluarga dan lingkungannya.

Secara umum, kebutuhan pembina pramuka adalah dari golongan anggota dewasa gerakan pramuka yang bertugas membina peserta didik di gugus depan setidaknya berkompetensi sudah KMD. Kendati demikian, golongan penegak dan pandega dapat diangkat sebagai pembina muda dan instruktur muda. Untuk usia penegak minimal usia 17 tahun boleh menjadi Pembina muda atau instruktur muda pada golongan pramuka siaga. Sedangkan bagi pandega boleh membina di golongan pengalang sekurang-kurangnya berusia 21 tahun. ${ }^{12}$ Dengan mengoptimalkan mahasiswa sebagai Pembina muda maka diperlukan upaya maksimal dalam memberikan kursus-kursus mahir dasar (KMD). Oleh karena itu, pembelajaran mata kuliah kepramukaan yang ada di

11 Arianto, J., Pengaruh unit kegiatan mahasiswa (UKM) pramuka terhadap pembentukan karakter jujur mahasiswa universitas Riau. Jurnal Perspektif Pendidikan dan Keguruan, 8(1), 2017.

12 AD dan ART Gerakan Pramuka, Keputusan Musyawarah Nasional X Gerakan Pramuka tahun 2018 nomor: 07/Munas/2018, (Jakarta: KwarNas Gerakan Pramuka, 2019) Pasal 28 ayat 1 (a) dan ayat 2 (a-b). h. 38-39. (Diakses 18 Februari 2020) 
program studi calon sarjana guru, perlu konsepsi pembinaan oleh pengampu mata kuliah bersama satu atau dua orang pendidik (team teaching). Bagaimana manajemen team teaching mata kuliah kepramukaan di program studi pendidikan dasar Islam? Artikel ini mencoba menguraikan konsepsi tersebut berdasarkan pendekatan konseptual.

\section{Pembahasan}

\section{Manajemen Team Teaching Kepramukaan}

Sebagaimana dijelaskan diatas bahwa tenaga pendidik dalam kepramukaan dan di perguruan tinggi bisa saling bersinergi dalam pengajaran, penelitian dan pengabdian. Anggota dewasa (dosen) yang minim dalam pengetahuan kepramukaan dan atau tidak memiliki kompetensi sebagai pendidik kepramukaan tentu saja tidak relevan bila mengampu mata kuliah kepramukaan yang telah dijadikan mata kuliah pendukung di program studi calon sarjana guru. Karena itu, keterlibatan pelatih pembina pramuka sangat urgen sebagai team teaching yang dimanajemen dengan baik. manajeman dalam konteks pendidikan merupakan proses pengaturan kerjasama secara sistemik dan komprehensif mencapai tujuan jangka pendek, menengah, dan panjang. ${ }^{13}$ Dapat juga di pahami suatu proses pengembangan kegiatan pembelajaran secara berkelompok (tim) melalui kerjasama dengan melakukan perencanaan, pengorganisasian, aktualisasi dan pengawasan mencapai tujuan pendidikan. ${ }^{14}$ Agar terjalin sinergi perencanaan sumber daya

\footnotetext{
${ }^{13}$ Moch. Mahsun, Implementasi Total Quality Management Dalam Pelayanan Penerimaan Mahasiswa Baru Di Institut Agama Islam Syarifuddin, Prosiding Seminar Nasional Pendidikan: Penguatan Pendidikan Karakter Dalam Profesionalisme Guru Generasi Milenial, Situbondo: Fakultas Keguruan dan Ilmu Pendidikan Universitas Abdurachman Saleh Situbondo. 2019, https://pgsd.unars.ac.id/wpcontent/uploads/2019/10/PROSIDING-SENADIK-2019.pdf\#page=66, (diakses 18 Maret 2020)

14 Moh. Yamin, Manajemen Mutu Kurikulum Pendidikan, Yogyakarta:Diva Press, 2009. Lihat juga E. Mulyasa, Manajemen Berbasis Sekolah, Bandung:PT. Remaja Rosdakarya, 2004.
} 
manusia berbakat dengan pengetahuan, kompetensi dan pengalaman serta karakter kepribadian etis unggul. ${ }^{15}$

Menurut Merril L. Meehan yang dikutip Dede Rosyada mengatakan bahwa team teaching dapat dipahami dengan adanya keterlibatan dua dosen atau lebih untuk bertanggung jawab dalam mengampu satu mata kuliah yang disampaikan kepada mahasiswa. Pelaksanaan proses pembelajaran itu, menurut Dede Rosyada, bisa dilakukan secara fleksibel dan luwes misalnya dengan pengelompokan mahasiswa kedalam beberapa kelompok, senyampang tetap pada target mencapai tujuan pembelajaran. ${ }^{16}$

Hal senada disampaikan oleh Winata, bahwa Team teaching, 'sejatinya' adalah terobosan efektif untuk meningkatkan kualitas pendidik secara akseleratif, akan saling melengkapi, menyempurkan dan bisa saling memberi semangat antara satu dengan lainnya. Sebagai strategi pembelajaran, menurutnya team teaching berfungsi mengorganisasikan dosen/guru sesuai kompetensi dan keahliannya. Kendatipun dalam praktiknya terdapat format yang berbeda-beda. ${ }^{17}$ Dalam perkembangannya, Wiradinata menyebutkan sedikitnya ada empat model team teaching yang bisa dilaksanakan oleh tim, yaitu;

Pertama; model supported Instruction. Model ini bagi salah satu dosen/guru menyampaikan materi, yang akan ditindaklanjuti oleh salah satu team lain. Kedua; model parallel instruction. Model ini dalam praktiknya bisa dilakukan dengan membagi mahasiswa/peserta didik menjadi dua kelompok. Dan masing-masing dosen dari team memberikan materi sesuai rencana. Ketiga; model differentiated split class. Model ini

\footnotetext{
${ }^{15}$ Moch. Mahsun, Talent Manajement di Perguruan Tinggi Islam pada Era Industri 4.0, seminar international, International Conference on Spirituality and Education for Civilization Sustainability in The IR 4.0 Era, Jember: IAIN Jember, 2019.

${ }^{16}$ Dede Rosyada, Team Teaching untuk Integrasi Sains dan Agama, di publikasikan pada 10 Februari 2015 dalam https://www.uinjkt.ac.id/team-teaching-untuk-integrasisains-dan-agama-2/, diakses pada 18 Maret 2020.

17 Wiradinata, D. R. Meningkatkan kualitas perkuliahan melalui team teaching. Edunomic, Jurnal Pendidikan Ekonomi, volume 1 Nomor 2, September 2013, 2013.
} 
hampir sama dengan model kedua, hanya saja pemilahan kelompok dilakukan untuk mengetahui tingkat pencapaian dari peserta didik. Agar team teaching bisa membagi tugas guna melakukan remedial hingga mencapai ketuntasan. Model keempat adalah monitoring teacher. Model ini dilakukan dengan cara, salah satu pendidik memberikan materi, sedangkan pendidik lainnya memonitor perilaku dan sikap para peserta didik. Keempat model tersebut bisa dikembangkan lagi sesuai dengan kreatifitas dan inovasi tim. Team teaching yang baik umumnya didasarkan pada prinsip kolegialitas (kebersamaan) dan kolaborasi (kemitraan). ${ }^{18}$

Sedangkan Lynn Cook dalam judul buku 'Co-Teaching Principles, Practice and Pragmatic", menurut Rosyada, menyebutkan ada enam teknik dalam pelaksanaan team teaching, yaitu;

"(1) One teach one observe (satu orang mengajar sedang lainnya melakukan observasi), (2) One teach one drif (satu pengajar memberikan materi, yang lain berputas melayani para pembelajar), (3) Parallel teaching (mahasiswa dikelompokkan kedalam beberapa kelas, dan diajar beberapa dosen), (4) Station teaching (membagi bahan ajar menjadi beberapa bagian, dan membagi mahasiswa pada sejumlah penggalan bahan ajar. Dimana masing-masing dosen berputar dari satu dosen pada dosen yang lain, (5) Alternative teaching (dua dosen mengajar bahan yang sama, satu pada mahasiswa kelompok kecil dengan perhatian ekstra sedangkan satu pada kelompok besar perlakuan biasa, dan (6) Team Teaching itu sendiri (dua dosen atau tiga atau lebih mengajar di kelas yang sama, bahasan yang sama, tapi masing-masing memiliki pengalaman berbeda yang saling melengkapi. ${ }^{19}$

Kedua pendapat diatas pada dasarnya memiliki persamaan pandangan tentang proses pembelajaran yang dilakukan oleh dua orang atau lebih dengan menyesuaikan dengan tugas dan kompetensi masingmasing. Sebagaimana dikatakan Smith dan Olve dalam judul artikelnya 'Team Teaching: Making Management Education More Student-Centred?"

\footnotetext{
${ }^{18}$ Wiradinata, D. R., Meningkatkan kualitas perkuliahan melalui team teaching. Edunomic, Jurnal Pendidikan Ekonomi, volume 1 Nomor 2, September 2013, 2013.

${ }_{19}$ Dede Rosyada, Team Teaching untuk Integrasi Sains dan Agama, di publikasikan pada 10 Februari 2015 dalam https://www.uinjkt.ac.id/team-teaching-untuk-integrasisains-dan-agama-2/, diakses pada 18 Maret 2020.
} 
menyatakan bahwa "..As a form of team teaching, the former implies that there must be a clear rationale for allocating responsibilities between teachers.." dengan kata lain, jalinan dua dosen dalam satu tim disesuaikan dengan memperjelas tanggung jawab masing-masing dosen/guru." 20

Dengan memperjelas masing-masing tugas dari team teacher tentunya memudahkan dalam melakukan penilaian terhadap peserta didik, termasuk ketika harus melakukan evaluasi secara terperinci dari sejak mengawali pembelajaran, kegiatan pembelajaran inti, hingga proses mengakhiri pembelajaran.

Dengan demikian, dapat dipahami bahwa melakukan manajemen team teaching untuk mata kuliah kepramukaan di perguruan tinggi, khususnya program studi calon sarjana guru dapat dilakukan secara dinamis dan sesuai dengan kebutuhan masing-masing koordinator atau penanggung jawab team teaching.

Jalinan sinergi antara lembaga pendidikan formal (perguruan tinggi) dengan lembaga pendidikan non-formal (gerakan pramuka) mewujudkan generasi sumber daya manusia yang selaras dengan cita-cita luhur Negara Kesatuan Republik Indonesia, merupakan upaya terus menerus dalam menciptakan dan mewujudkan kader kepemimpinan yang handal dan profesional.

Karena itu, dalam pembelajaran mata kuliah kepramukaan diperlukan keterlibatan para pelatih pembina pramuka. pelatih pembina pramuka yang terwadahi di dalam pusat pendidikan dan pelatihan (pusdiklat) gerakan pramuka mulai tingkat nasional, daerah hingga cabang di masing-masing kwartir sepatutnya diajak kerjasama dan menjadi team teaching dalam pendidikan kepramukaan. Kerjasama dapat dilakukan dalam bentuk penandatanganan (MoU) antara pemangku kebijakan di masing-masing fakultas atau program studi calon sarjana

${ }^{20}$ Easterby-Smith, M., \& Olve, N. G., Team Teaching: Making Management Education more student-centred?. Management Education and Development, Vol. 15, pt, 3,. 1984. https://doi.org/10.1177/135050768401500305 (diakses 18 Maret 2020) 
guru; baik Dekan, Kaprodi dan atau lainnya agar dapat menyelenggarakan kegiatan pendidikan dan pelatihan kepramukaan bersinergi dengan tri darma perguruan tinggi (pengajaran, penelitian 'publikasi', dan pengabdian masyarakat).

Pembelajaran kepramukaan pada mahasiswa program studi calon sarjana guru menuntut upaya persuasif dan intensif dalam memahami gerakan Pramuka. Adalah hal yang relevan bagi mahasiswa calon sarjana guru, adapun penyesuaian diri pendidik memahami pentingnya penguasaan teori kepramukaan. Sebagai objek kajian akademis, kepramukaan merupakan bahasan penting bagi program studi-program studi ilmu Pendidikan. Saat ini, perguruan tinggi keagamaan Islam (PTAI) baik negeri atau pun swasta, pada umumnya prodi pendidikan guru madrasarah Ibtidaiyah (PGMI) yang telah menetapkan mata kuliah kepramukaan sebagai pendukung kompetensi mahasiswa. Sedangkan program studi ilmu pendidikan lain seperti Pendidikan Agama Islam (PAI), Manajemen Pendidikan Islam (MPI), pendidikan bahasa arab (PBA), pendidikan bahasa Inggris (Tadris), dan lainnya belum memberikan pilihan bagi para mahasiswanya. Kalaupun ada, masih sangat sedikit. Hal itu perlu menjadi pertimbangan bagi para pemangku kebijakan kampus, bukan sebatas pada tataran mahasiswa, melainkan juga kepada para dosen sebagai anggota dewasa.

Pada dasarnya proses keaktifan masing-masing mahasiswa dalam gerakan pramuka adalah berdasarkan kesukarelaan, namun tahap penguasaan ilmu pendidikan bagi calon sarjana pendidik dipandang cukup signifikan dalam memahami kepramukaan dan gerakan pramuka. Implementasi penguatan kepramukaan bagi calon sarjana pendidik bisa ditunjukkan dengan menjadikan kepramukaan sebagai bagian pilihan mata kuliah pendukung kompetensi lulusan. Karena itu, mata kuliah kepramukaan diberikan porsi tersendiri dalam sistem kredit semester (SKS). Mahasiswa calon guru diharapkan memahami kepramukaan secara 
komprehensif, apalagi mahasiswa calon sarjana di dukung dengan kepemilikan ijazah kompetensi pembina pramuka pasca kursus mahir dasar (KMD) dan juga lanjutan (KML).

\section{Penyelenggaraan Kursus Mahir Dasar}

Dalam rangka meningkatkan kompetensi mahasiswa program studi pendidikan dasar Islam melalui kurikulum kepramukaan, ketua program studi perlu merencanakan terselenggaranya kursus mahir tingkat dasar (KMD) bagi mahasiswa yang telah menempuh pemograman kepramukaan. KMD yang diperuntukkan bagi mahasiswa calon sarjana pendidik atau lainnya, harus memenuhi persyaratan sebagai calon peserta kursus. Penyelenggaran bisa dilaksanakan bekerjasama dengan pusat pendidikan dan pelatihan (Pusdiklat) cabang di tingkat kota/kabupaten.

Penyelenggaraan dan pelaksaan kursus mahir dasar dan lanjutan sebagaimana keputusan kwarnas nomor 179 tahun 2010 merupakan tugas pokok dan fungsi kwartir cabang oleh para pelatih pusdiklatcab. Fungsinya adalah meningkatkan jumlah (kuantitas) dan mutu (kualitas) anggota gerakan pramuka. Penyelenggaraan KMD golongan siaga misalnya, secara nasional berlangsung selama 70 jam pelajaran (jp), yaitu;

"Pertama; Materi yang alokasinya satu jam pelajaran sedikitnya ada delapan jenis (upacara pembukaan, tes awal, orientasi kursus, kontrak belajar, tes akhir, RTL, open forum dan evaluasi, dan upacara penutupan). Kedua; Materi yang alokasinya dua jam pelajaran (jam pimpinan kebijakan gerakan pramuka dan kwartir, muatan lokal, refleksi atau renungan kursus dan pelaksanaan api unggun). Ketiga; Materi yang alokasinya tiga jam pelajaran; (1) Materi tentang postur pembina terdiri dari; jiwa, peran, fungsi dan tugas Pembina siaga; membina siaga dengan sistem among; seragam, tanda penghargaan, tanda jabatan dan tanda pengenal Pembina pramuka. (2) materi tentang organisasi, administrasi gudep dan satuan. (3) materi mengenal dunia siaga, (4) materi ragam upacara dalam satuan siaga, (5) materi teknik penyusunan program latihan siaga. Keempat; Materi yang alokasinya empat jam pelajaran; (1) materi fundamental gerakan pramuka, (2) materi dunia siaga; karakteristik anak usia pramuka siaga, jenjang tingkatan usia pramuka siaga, seragam dan tanda pengenal pramuka siaga, prodik pramuka siaga, (3) materi metode membina 
pramuka siaga; mengenali ragam metode membina, mengidentifikasi cara belajar efisien dan efektif, menentukan metode membina pramuka siaga yang sesuai tujuan, (4) materi tatalaksana perkemahan, (5) materi ragam keterampilan bagi siaga, (6) materi syarat kecakapan umum (SKU), SKK, syarat pramuka garuda (SPG), dan pelantikan siaga, (7) materi ragam pertemuan pramuka siaga, (8) materi membina pramuka siaga. Kelima; Materi yang alokasinya sebanyak lima jam pelajaran, yaitu; prinsip dasar kepramukaan mencakup metode kepramukaan, kiasan dasar, dan sistem among. Adapun maksud pelaksanaan kursus pembina pramuka mahir tingkat dasar adalah agar menjadi bekal pengetahuan dasar sekaligus pengalaman praktis pembinaan pramuka melalui kepramukaan dalam satuan pramuka; siaga, penggalang, penegak, dan pandega. ${ }^{21}$

Kursus mahir dasar diperuntukkan bagi anggota dewasa dan anggota muda (utamanya pandega) yang akan membantu membina di gugusdepan. Lulusan KMD wajib mendapatkan SK dan sertifikat Narakarya I, kemudian melaksanakan pengembangan dalam pembinaan selam enam bulan didampingi seorang pelatih pembina yang ditugaskan oleh kwarcabnya. Setelah narakarya I selesai, berhak mendapatkan surat keputusan terkait penyelesaian narakarya dan kemudian mendapatkan surat Hak Bina (SHB). Pada tahap berikutnya setelah mendapatkan penilaian bisa melanjutkan ke jenjang kursus mahir lanjutan (KML).

\section{Kesimpulan}

Kesimpulan penelitian yaitu; pertama; team teaching dimulai dan atas dasar adanya MoU antara program studi atau fakultas dengan pelatih pembina pramuka. Kedua; team teaching kepramukaan berkolaborasi secara berkelanjutan dalam pelaksanaan atau pendidikan kursus mahir dasar dan lanjutan. Ketiga; team teaching penguatan peran pusdiklat dan puslitbang dalam penelitian-publikasi dan pengabdian masyarakat bidang kepramukaan. Keempat; team teaching dalam penilaian pendistribusian mahasiswa pembina pramuka bagi golongan siaga dan penggalang sebagai uji kompetensi calon guru profesional secara berkelanjutan.

${ }^{21}$ Buku pedoman pelaksanaan kursus mahir Pembina pramuka tingkat dasar nomor 090 tahun 2001. 


\section{Daftar Pustaka}

Arianto, J., 2017, Pengaruh unit kegiatan mahasiswa (UKM) pramuka terhadap pembentukan karakter jujur mahasiswa universitas Riau. Jurnal Perspektif Pendidikan dan Keguruan, 8 (1).

Arfiah, Sri dan Agung Prasetya, 2017, Pembelajaran kepramukaan dalam penguatan Karakter Kemandirian dan tanggungjawab dalam upaya mempersiapkan mahasiswa PPKN sebagai Pembina Ekstrakurikuler di Sekolah, URECOL.

Al Azizi, Nur Qoyimatul Uyun, 2018, Kegiatan ekstrakurikuler kepramukaan terhadap pendidikan karakter kedisiplinan. Jurnal Pendidikan Luar Sekolah, Vol. 12, No. 2.

AD dan ART Gerakan Pramuka, 2019, Keputusan Musyawarah Nasional X Gerakan Pramuka tahun 2018 nomor: 07/Munas/2018, Jakarta: Kwarnas Gerakan Pramuka.

Easterby-Smith, M., \& Olve, N. G. 1984. Team teaching: making management education more student-centred?. Management Education and Development, Vol. 15, pt, 3.

Erliani, Saadah, 2017, Peran Gerakan Pramuka Untuk Membentuk Karakter Kepedulian Sosial Dan Kemandirian (Studi Kasus Di Sdit Ukhwah Dan Mis An-Nuriyyah 2 Banjarmasin), Al-Adzka: Jurnal Ilmiah Pendidikan Guru Madrasah Ibtidaiyah [Online].

Intan, Kusumawati, 2012, Pembentukan karakter siswa melalui pendidikan kepramukaan. Academy of Education Journal, 3 (1).

Kwartir Nasional, 2001. Buku pedoman pelaksanaan kursus mahir Pembina pramuka tingkat dasar nomor 090.

Moch. Mahsun, 2019, Talent Manajement di Perguruan Tinggi Islam pada Era Industri 4.0, International Conference on Spirituality and Education for Civilization Sustainability in The IR 4.0 Era, Jember: IAIN Jember, 2019.

Mahsun, Moch, 2019, Implementasi Total Quality Management Dalam Pelayanan Penerimaan Mahasiswa Baru Di Institut Agama Islam Syarifuddin, prosiding Seminar Nasional Pendidikan: Penguatan Pendidikan Karakter Dalam Profesionalisme Guru Generasi Milenial, Situbondo: Fakultas Keguruan dan Ilmu Pendidikan Universitas Abdurachman Saleh Situbondo. https://pgsd.unars.ac.id/wpcontent/uploads/2019/10/PROSIDING-SENADIK-2019.pdf\#page=66, (diakses 18 Maret 2020)

Mulyasa, E., 2004, Manajemen Berbasis Sekolah, Bandung, PT. Remaja Rosdakarya.

M., Wangid, 2009, Sistem among pada masa kini: kajian konsep dan praktik pendidikan. Jurnal Kependidikan: Penelitian Inovasi Pembelajaran, 39(2).

R., Wiradinata, D., 2013, Meningkatkan kualitas perkuliahan melalui team teaching. Edunomic, Jurnal Pendidikan Ekonomi, volume 1 Nomor 2.

Wekke, Ismail Suardi, 2018, Tata Kelola Pembinaan Pramuka Di Perguruan Tinggi. Makalah kursus pelatih dasar (KPD) Kwarda Bandar Lampung 23 Februari s.d 1 Maret 2018.

Yamin, Moh. 2009, Manajemen Mutu Kurikulum Pendidikan, Yogyakarta, Diva Press. 
Rustam Supriyanto, Farhan

16 | Bidayatuna, Vol. 03 No. 01 April 2020 